\title{
Conceptual design of jewellery: a space-based aesthetics approach
}

\author{
Vaia Tzintzi ${ }^{1}$, Athanasios Manavis ${ }^{1}$, Nikolaos Efkolidis ${ }^{1}$, Christos Dimopoulos ${ }^{2}$, \\ Konstantinos Kakoulis ${ }^{1}$ and Panagiotis Kyratsis ${ }^{1, *}$ \\ ${ }^{1}$ Western Macedonia University of Applied Science, Department of Mechanical Engineering and \\ Industrial Design, Kila Kozani GR50100 Greece \\ ${ }^{2}$ European University Cyprus, School of Sciences, Nicosia, Cyprus
}

\begin{abstract}
Conceptual design is a field that offers various aesthetic approaches to generation of nature-based product design concepts. Essentially, Conceptual Product Design (CPD) uses similarities based on the geometrical forms and functionalities. Furthermore, the CAD-based freehand sketch is a primary conceptual tool in the early stages of the design process. The proposed Conceptual Product Design concept is dealing with jewelleries that are inspired from space. Specifically, a number of galaxy features, such as galaxy shapes, wormholes and graphical representation of planet magnetic field are used as inspirations. Those space-based design ideas at a conceptual level can lead to further opportunities for research and economic success of the jewellery industry. A number of illustrative case studies are presented and new opportunities can be derived for economic success.
\end{abstract}

\section{Introduction}

The conceptual design inspired from different science fields can become a straightforward activity for the industrial designers. Specifically, several designers from different backgrounds (i.e., furniture design, fashion, transportation and architectural design) are using nature and its evolution as an inspiration for their product designs [1]. The main reason of that are the opportunities created for innovation and creativity (Figure 1). Essentially, conceptual design is a field that offers various aesthetic approaches to generation of naturebased product design concepts. The term nature can be defined as both the earthly nature and at the same time the outer space nature.

Jewellery design has been around for thousands of years. It has changed and further developed over the years. Valuable metals and precious stones are designed, processed together for jewellery creations. Jewels are based on aesthetics but can incorporate different concepts related to religion. Jewellery is the peak where beauty, even passion, is combined with immortality [2]. Contemporary jewellery is an extremely exciting field which explores

\footnotetext{
*Corresponding author: pkyratsis@teiwm.gr
} 
many new and innovative materials and techniques (i.e., CAD systems, rapid prototyping and 3D scanning methods, laser cutting and engraving systems etc.).

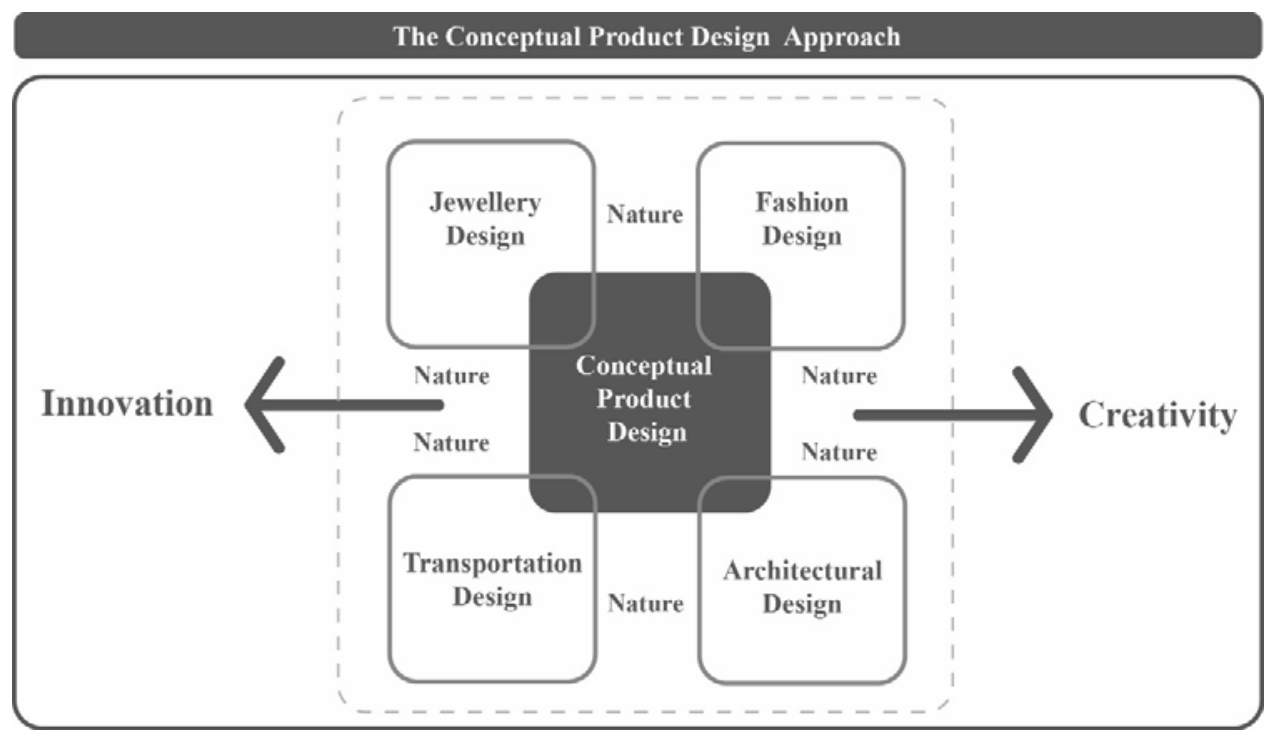

Fig. 1. The Conceptual Product Design approach.

\section{Nature-based design approach}

Humans have always been inspired by nature capabilities in problems solving and innovation [3]. There is a great number of nature-inspired design approaches that were developed in the recent years, i.e. structural design and morphology, material and texturing. The main advantage of bio-inspired design methods consists in offering designers an organized process for attaining a model that may be applied in design [4]. Final creations could be based on the relations between function, ergonomic features and aesthetics of nature.

Structural design is one of the most important components of any entity in the universe, which has a physical dimension. The term structural design means: the art and science of creating a structural system in nature or in the artificial world [5]. The structural systems in nature have two directions: a) structural systems in living systems and b) structural systems in inanimate entities.

Material selection for a clear-cut nature-based application is a thorough, lengthy and expensive process. There are many constraints to be considered in selecting materials. There are some situations that certain criteria for a material are defined at the beginning of the design project. Designer selects a material and he/she must consider fulfilling the three basic requirements: a) service requirements, b) fabrication requirements and c) economic requirements. On the other hand, the designers might be very attentive about the aesthetics criteria of material, such as colour and texture [6].

\subsection{Conceptual Product Design Framework}

Conceptual Product Design (CPD) is more of an art than an actual science. The framework followed from industrial designers incorporates several sessions of creative processes (i.e. brainstorming, mind-map and mood boards) with an aim to find alternative ideas for each 
product. Each idea inspired from nature was associated with the final products in order to inspire further the process of ideas generation.

CAD-based sketches were used so as to outline each idea at a conceptual design level and all of them were presented to an audience (designers, artists, engineers and marketers). The team of all these specialists was able to make comments about the ideas by completing a short questionnaire. An additional outcome was that these possible future customers would be willing to pay more for purchasing a product with a specific concept inspired from nature (Figure 2). The audience consisted of 18 students of the Master's program in Product Design and Systems.

The Conceptual Product Design Framework (CPD)

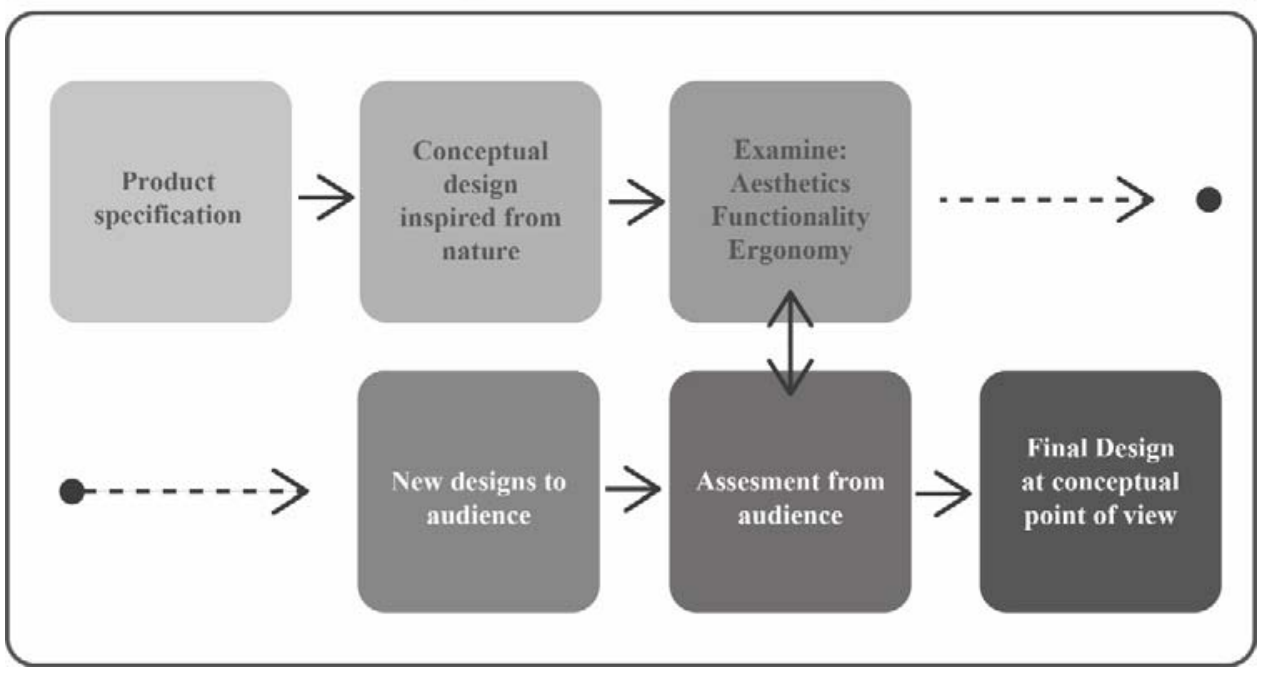

Fig. 2. The conceptual product design framework.

\subsection{Jewellery industry}

Jewellery is a universal form of adornment. They are made of shells and stone from prehistoric times [7]. The main themes of the first jewelleries were the flowers and the floral motifs. It is clear that the nature was the first inspiration for the jewellery industry.

Today, the boundaries of jewellery have been continually redefined. Conventions have been challenged by successive generations of industrial designers, often educated at art and design schools and immersed in radical ideas. New technologies, innovative design concepts and modern materials have overturned the notions of status traditionally implicit in jewellery.

\subsection{Inspirations from space}

The cosmic theme always awakens insatiable curiosity. This specific nature (planets, asteroids, stars, galaxies, black holes, and satellites) is not often used as a design concept for product designers. Moreover, the term inspired from nature design is considered more related to earth based nature. For this reason, the space-based aesthetics design approach offers a great advantage for the industrial designers. The specific inspiration, at a conceptual level, can lead to further opportunities for research and economic success. Innovative and novel ideas can be created and offer a great deal of satisfaction to the appropriate customer groups. 


\section{Conceptual case studies for the jewellery industry}

The current paper presents a series of products, at conceptual level, inspired from nature. The proposed CPD concept is about jewelleries that are inspired from space. A number of galaxy features, such as galaxy shapes, wormholes and graphical representation of planet magnetic fields are used as an inspiration.

- Ring design based on a wormhole visualisation. A ring is a round band, usually of high quality and made of precious metals, worn as an ornamental piece around the finger. There are different types of rings, depending on their shape, material, use or meaning. Some of these rings have a symbolic function such as the wedding band. In this case, a ring proposal is presented based on the form of a wormhole.

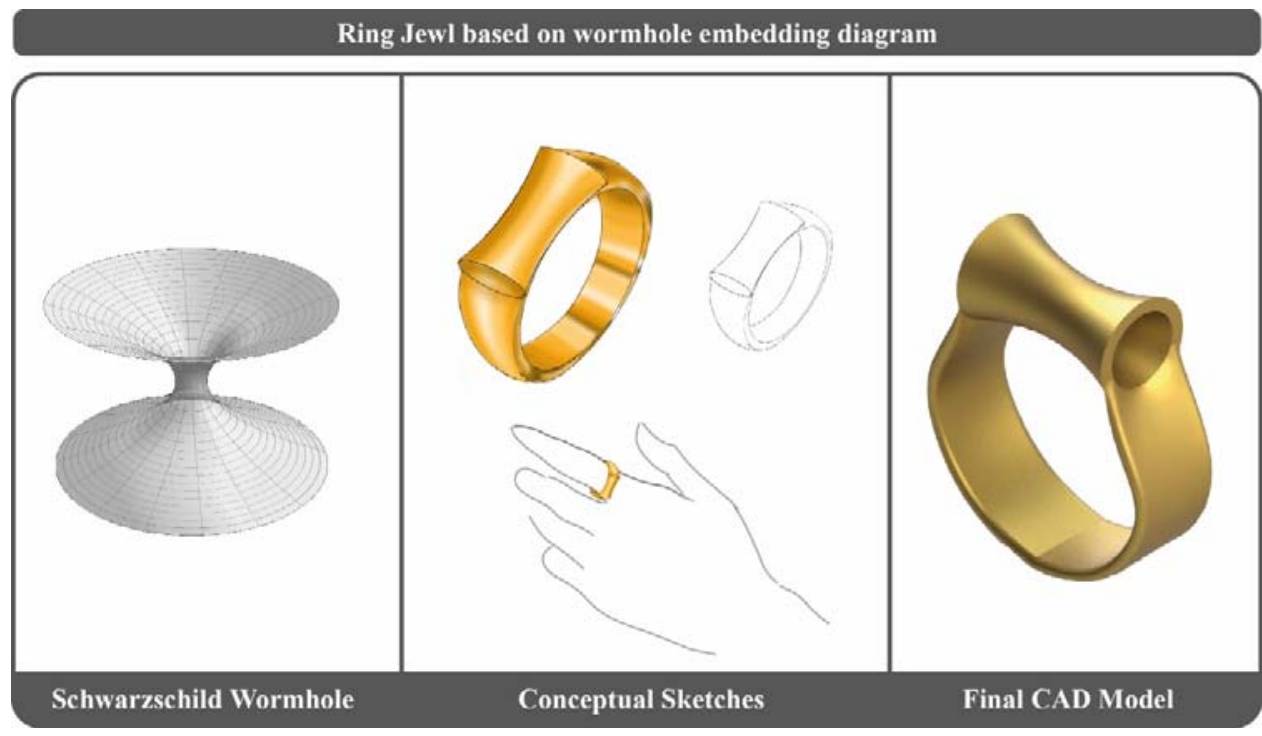

Fig. 3. A ring design based on the wormhole embedding diagram.

A wormhole is a hypothetical shortcut between two distant regions of a space-time. A three dimensional wormhole is impossible to be fully visualized. However, there is a humanfriendly approach of the wormhole visualization. It is known as Schwarzchild embedding diagram, which is the wormhole analogue for a static, non-rotating, Schwarzchild black hole. The proposed product of the ring incorporates all these special geometries together with the aesthetics elements that excuse the wormhole concept (Figure 3).

- Earring design based on the Earth's magnetic field. An earring is a piece of jewelry attached to the ear via a piercing in the earlobe or another external part of the ear. They are the most essential jewelry item for every woman, they sparkle and shine and add much glamor to their appearance. There are different types of earrings. The categorization is based on different types of closures: posts, fish hook, lever backed, kidney and hoop. In this case, the presented earrings are inspired from the geometrical characteristics of the earth's magnetic field (Figure 4). The earth is considered a large size magnet, generating a great deal of magnetic field around itself. The view of the magnetic field used, at a conceptual level, is based on real science observations that have been made since the beginning of the space age. The magnetosphere bulges on one side and tapers off on the other, because it is pushed on the side facing the sun by the solar wind and stretched out in the earth's shadow. These specific lines were used as the main inspiration for the earring design. 


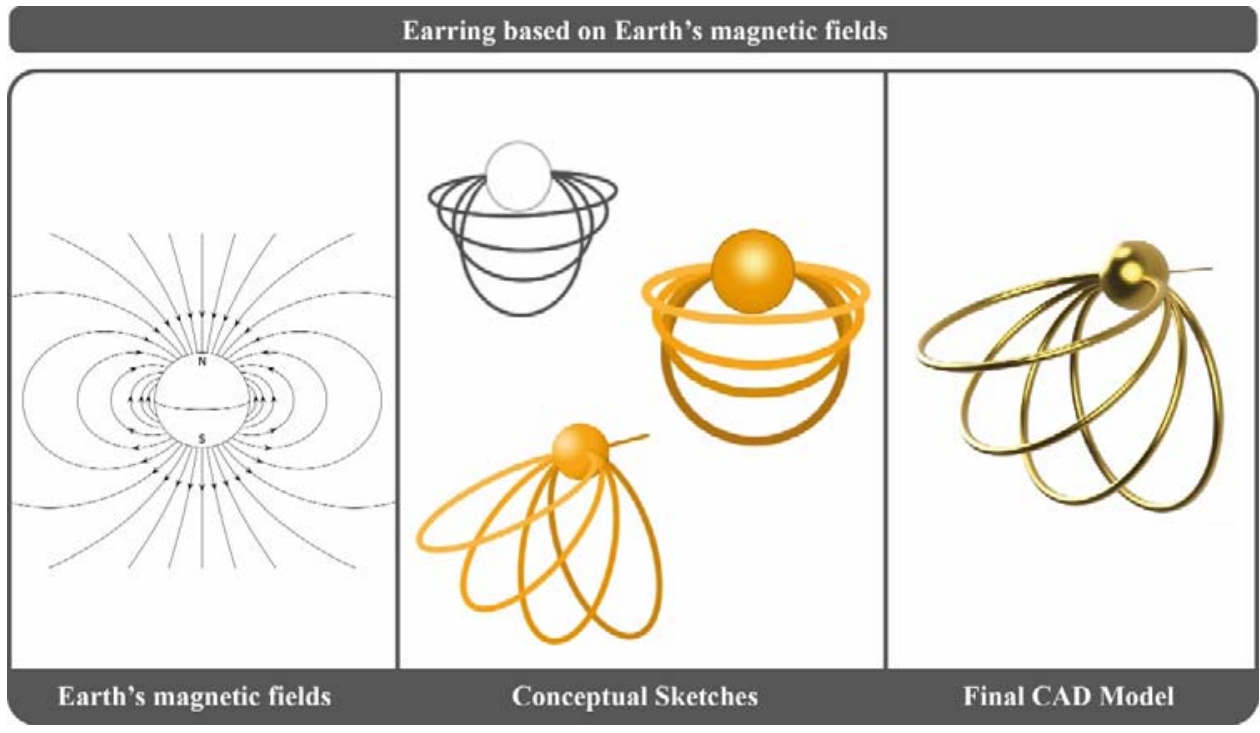

Fig. 4. Earrings design based on the geometrical characteristics of earth's magnetic field.

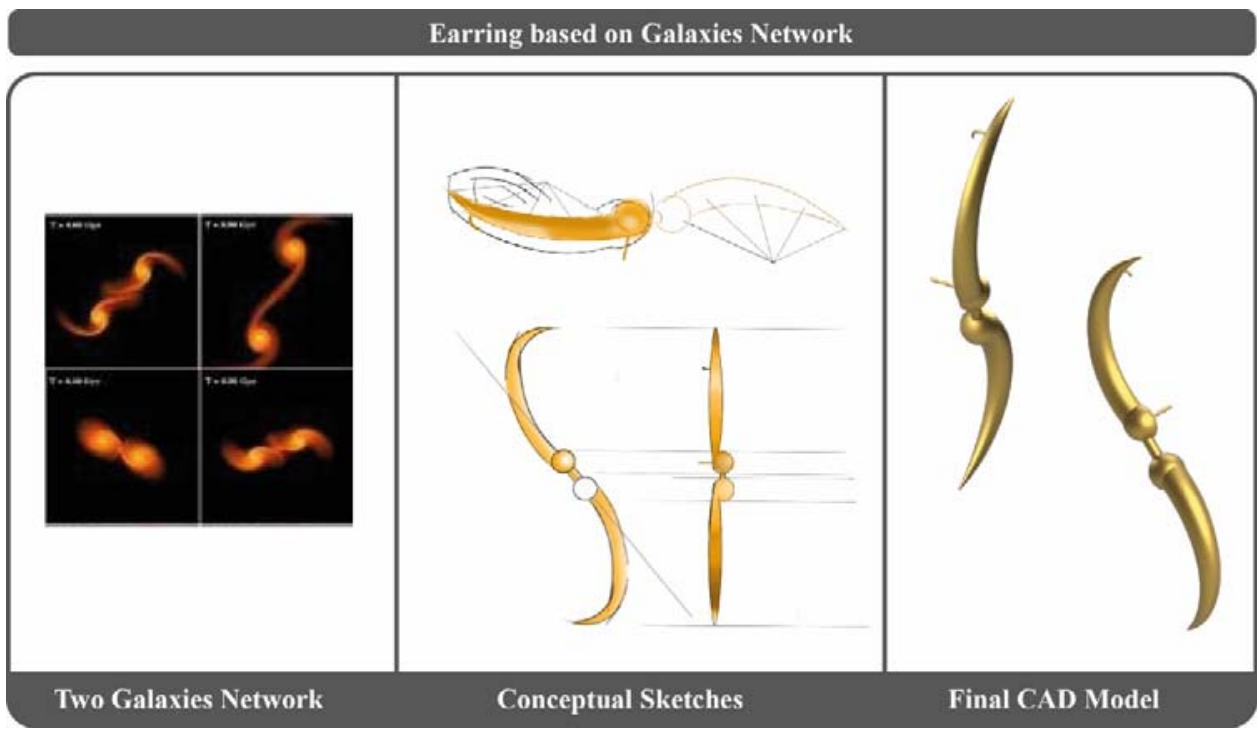

Fig. 5. Earring design based on galaxies network.

- Earring design based on galaxies network. Galaxies interact with each other and are considered connected with other galaxies by gravity. Galaxy groups can be small (two galaxies orbiting each other), or large (cluster of thousands of galaxies extending for more than ten million light years). Clusters are made up of two basic types of matter: luminous matter (i.e. stars, hot gas) and dark matter. Dark matter does not shine on its own, and the only way we know it exists is because of its gravitational effect on luminous matter [8]. The final result of earring has all these specific aesthetics elements that are described for the small group of two galaxies (Figure 5). The key features of the proposed design are based on the orbital geometry between two galaxies. 


\section{Conclusions}

A series of conceptual product designs were presented based on the design inspired from space.

The CPD framework provides a stable process for assessing the proposed products. Following the Conceptual Product Design framework industrial designers are able to follow a structured way for presenting novel ideas for products that are able to offer commercial success and communicate their messages to the future customers.

Those space-based design ideas at a conceptual level can lead to further opportunities for research and economic success for jewellery industry.

The methodology is considered to be an extension of the design inspired from nature.

\section{References}

1. P. Kyratsis, E. Dimou, A. Manavis, N. Bilalis, $A M M, \mathbf{7 6 0}, 33$ (2015)

2. L. Ulusman, Ç. Bayburtlu, Procedia Soc. Behav. Sci., 46, 5928 (2012)

3. Y. Bar-Cohen, Int. J. Aeronaut. Space, 13(1), 1 (2012)

4. C.A.M. Versos, D.A. Coehlo, Biologically inspired design: Methods and validation, (Industrial Design-New Frontiers, 2011)

5. A. Mosseri, WIT Trans. Ecol. Envir., 73, 589 (2011)

6. E. Karana, P.Hekkert, P. Kandachar, Smart Design: $1^{\text {st }}$ International Conference Proceedings, 29, 1081 (2008)

7. L.C. Molinari, M.C. Megazzini, E. Bemporad, Gold Technol., 23, 3 (2008)

8. https://imagine.gsfc.nasa.gov/science/objects/clusters.html Accessed 22/02/2017 